\title{
Shrinkage Effects of the Conduction Zone in the Electrical Properties of Metal Oxide Nanocrystals: The Basis for Room Temperature Conductometric Gas Sensor
}

\author{
M. Manzanares, ${ }^{1}$ T. Andreu, ${ }^{1}$ J. D. Prades, ${ }^{1,2}$ J. Arbiol, ${ }^{1,3}$ F. Hernandez-Ramírez,, 4 \\ A. Cirera, ${ }^{1}$ and J. R. Morante ${ }^{1,2}$ \\ ${ }^{1}$ EME/XaRMAE/IN ${ }^{2} U B$, Departament d'Electrònica, Universitat de Barcelona, C/ Martí i Franquès, 1.08028 Barcelona, Spain \\ ${ }^{2}$ IREC, Institut de Recerca en Energia de Catalunya, C/Josep Pla 2, B2, ground floor, 08019 Barcelona, Spain \\ ${ }^{3}$ TEM-MAT, Serveis Cientificotècnics, Universitat de Barcelona, 08028 Barcelona, Spain \\ ${ }^{4}$ Electronic Nanosystems, SL.08028 Barcelona, Spain
}

Correspondence should be addressed to M. Manzanares, mmanzanares@el.ub.es

Received 23 January 2009; Accepted 21 May 2009

Recommended by Yongxiang Li

The influence of charge localized at the surface of minute metal oxide nanocrystals was studied in $\mathrm{WO}_{3}$ and $\mathrm{In}_{2} \mathrm{O}_{3}$ nanostructures, which were obtained replicating mesoporous silica templates. Here, it is shown that the very high resistive states observed at room temperature and dark conditions were originated by the total shrinkage of the conductive zone in the inner part of these nanocrystals. On the contrary, at room temperature and under UV illumination, both photogenerated electron-hole pairs and empty surface states generated by photons diminished the negative charge accumulated at the surface, enlarging the conductive zone and, as a consequence, leading to a reduction of the electrical resistance. Under these conditions, empty surface states produced by UV light reacted with oxidizing gaseous molecules. The charge exchange associated to these reactions also affected the size of the inner conductive zone, and leaded to a new steady-state resistance. These chemical, physical and geometrical effects can be used for gas detection, and constitutes the basis for developing novel room temperature conductometric gas sensors responsive to oxidizing species.

Copyright (c) 2009 M. Manzanares et al. This is an open access article distributed under the Creative Commons Attribution License, which permits unrestricted use, distribution, and reproduction in any medium, provided the original work is properly cited.

\section{Introduction}

It is well known that the response of conductometric solid state gas sensors based on thin or thick films increases with the surface-to-volume ratio of the crystallites inside them. During the last decades, many efforts have been undertaken to reduce the grain size of these polycrystalline films to values below a few tens of nanometers. To achieve this goal, new wet chemical routes or modified physical deposition techniques have been used $[1,2]$. In parallel to this scalingdown approach, the use of sensitive layers formed by bundles of nanowires has been proposed as well. However, the surface-to-volume ratio of the nanowires is not higher than the values reached with nanocrystals, and any significant improvement in the final performance of these prototypes was reported $[3,4]$.
It is noteworthy that the use of sensing films leads to other inherent restrictions such as gas diffusion in their inside, chemical sensing inhomogeneity, grain agglomeration and intergrain-boundary effects. Each one of them modifies the behavior of the prototypes and hampers the study of the grain size influence on the ideal sensor response expected in a scenario free of interfering effects [5-7].

The study of individual nanowires offers an excellent opportunity to avoid many of these interferences [8]. Furthermore, the direct influence of the nanowire radius on the sensor response has also been reported [9]. According to these results, response towards gases sharply increases with radii below $15 \mathrm{~nm}$. In this situation, the conduction channel along the nanowire is close to total depletion and small variations in the charge trapped at the surface by gaseous molecules lead to huge effects on their electrical responses. 
Typical sizes for depleted regions in metal oxides are close

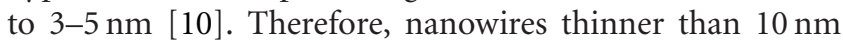
in diameter are considered excellent candidates to both study deep depletion effects and understand the complete shrinkage of the conductive zone. Unfortunately, there are still important technical drawbacks to manipulate and electrically contact individual ultrathin nanowires, hindering the fabrication of experimental prototypes.

In this paper, we report an alternative approach to study the shrinkage effects of the conductive zone in nanostructured metal oxides, overcoming the technical limitations associated with nanowires. This approach is based on the use of nanostructured $\mathrm{In}_{2} \mathrm{O}_{3}$ and $\mathrm{WO}_{3}$ obtained as replicas of mesoporous templates [11, 12]. This method produces minute nanograins ordered in a network that facilitates gas diffusion through it, maintains the chemical sensing homogeneity, avoids grain agglomeration and diminishes grain boundary effects [13-15]. UV illumination is used to modulate their resistance several orders of magnitude, changing from an insulating to a semiconductor state useful for gas sensing applications even at room temperature. Likewise, surface functionalization is used to modify the density of active sites at the surface and, thus, to balance the influence of the surface and bulk effects on the overall response. This approach, that combines fully depleted nanomaterials with UV illumination and surface functionalization, opens the door to the development of room temperature conductometric gas sensors.

\section{Experimental Setup}

2.1. Synthesis Routes. As previously discussed, the use of templates is an attractive alternative to overcome the abovementioned difficulties concerning the fabrication of the sensors and the interpretation of their response.

The soft-template methods, based on the use of surfactants, were initially discarded. Even though these methods reduce the dispersion of the particles, the fact that the template is removed before annealing produces agglomerated materials. In contrast, the template is removed in the hardtemplate methods afterwards, and this ensures a good control of the particle size since the template acts as a physical barrier to coalescence of the crystals during the calcination process.

The hard-template method also offers several additional advantages. Firstly, it allows obtaining a porous network distribution that depends on the nanotemplate structure, selected among a wide variety, such as MCM-41, SBA-15, KIT-6, and SBA-16. Second, the replication process using silica templates is easy to scale-up. This is an advantage compared with other hard-templates such as anodized aluminum oxides (AAOs) membranes. Third, mesoporous silica templates offer good thermal stability for the synthesis of metal oxides at relatively high temperatures [16].

Mesoporous silica was synthesized by using a nonionic triblock copolymer surfactant (EO20PO70EO20, Pluronic P123 from BASF) as a structure directing agent [17]. In this work, we have chosen the KIT-6 structure (threedimensional cubic Ia3d) for the mesoporous silica template $[18,19]$. KIT- 6 was synthesized using the following proce- dure: $6 \mathrm{~g}$ of $\mathrm{P} 123$ were dissolved in $195 \mathrm{~g} \mathrm{H}_{2} \mathrm{O}, 30 \mathrm{~g}$ of $\mathrm{HCl}$ $37 \%$ and $6 \mathrm{~g}$ of 1-butanol. Then, $12.5 \mathrm{~g}$ of TEOS (tetraethyl orthosilicate) were added dropwise, and the mixture was stirred for $24 \mathrm{~h}$ at $36^{\circ} \mathrm{C}$, followed by a hydrothermal treatment at $90^{\circ} \mathrm{C}$. Finally, the mesoporous silica was filtered, washed, dried and calcinated at $550^{\circ} \mathrm{C}$.

For obtaining mesoporous indium oxide or tungsten oxide, a two-impregnation process was performed. In a typical synthesis, $0.15 \mathrm{~g}$ of mesoporous silica (KIT-6) were firstly impregnated, respectively, with $1 \mathrm{mmol}$ of $\mathrm{In}\left(\mathrm{NO}_{3}\right)_{3} \cdot \mathrm{xH}_{2} \mathrm{O}$ ethanolic solution or with phosphotungstic acid (Alfa Aesar) which was used as a precursor for $\mathrm{WO}_{3}$. The mixture was stirred for 30 minutes, dried and calcinated at $350^{\circ} \mathrm{C}$. The resulting powder was impregnated again with the precursor and calcinated at higher temperature than $600^{\circ} \mathrm{C}$ in order to obtain the metal oxide as a well-stabilized material. Finally, the silica template was removed by etching the material with a $2 \mathrm{M} \mathrm{NaOH}$ solution at $70^{\circ} \mathrm{C}$ for 24 hours or alternatively with HF. The solid was separated by centrifugation and cleaned several times with water and ethanol. In all cases, chemicals were of analytical grade and water used had been distilled twice and disionized with a Millipore Milli-Q system. XPS and EELS analyses revealed that all the silica was completely removed, at least, within the resolution limits of these techniques.

Some samples were functionalized with aminopropylphosphonate [20]. Since $\mathrm{P}-\mathrm{O}-\mathrm{M}$ bonds are more thermodynamically stable than $\mathrm{Si}-\mathrm{O}-\mathrm{M}$ bonds, phosphonate blocks the surface sites in the right direction. In addition to this, the reaction of metal oxides with phosphonate is easier even in the absence of hydroxyl groups.

2.2. Material Characterization. X-Ray Diffraction (XRD) analysis was performed on Siemens D500 and Bruker D4 X-ray Powder diffractometers, working with the $\mathrm{Cu}$ $\mathrm{K}_{\alpha}$ radiation. Transmission Electron Microscopy (TEM) characterization was carried out using a Philips CM30 SuperTwin electron microscope operating at $300 \mathrm{keV}$ and High Resolution TEM (HRTEM) was performed on a JEOL JEM $2010 \mathrm{~F}$ electron microscope operating at $200 \mathrm{keV}$ with a field emission gun. X-Ray Photoelectrons Spectroscopy (XPS) measurements were performed on a PHI equipment 5500 Multitechnique model, operating with $\mathrm{Al} \mathrm{K}_{\alpha}$ line at $1486.6 \mathrm{eV}(0.9 \mathrm{eV}$ of line width). Brunauer-Emmett-Teller (BET) analysis was performed using ASAP 2000 equipment (Micrometrics). For this purpose, samples were degassed at $150^{\circ} \mathrm{C}$ for 20 hours in a maximum vacuum of $266 \mathrm{~Pa}$. Both porous replicas displayed high superficial specific area $\left(65 \pm 5 \mathrm{~m}^{2} \mathrm{~g}^{-1}\right)$ which was in range with the values obtained for the silica template $\left(62 \pm 5 \mathrm{~m}^{2} \mathrm{~g}^{-1}\right)$.

2.3. Sensors Fabrication and Measurement. Sensors were prepared by screen-printing of the as-synthesized powders and an organic solvent (1,2-propanediol) mixture onto alumina substrates. Platinum electrodes and a platinum heater had been previously printed at front and back sides of the substrates. Platinum heater allowed controlling the working temperature. Sensors were fired at $500^{\circ} \mathrm{C}$ for 30 minutes to evaporate the solvent and to ensure sample adherence to the 


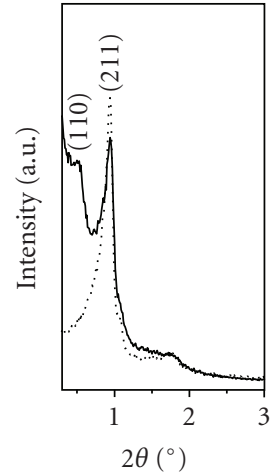

(a)

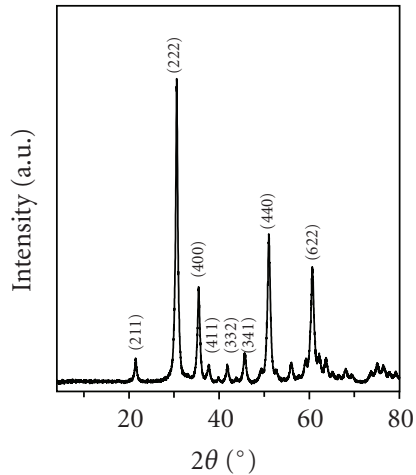

(b)

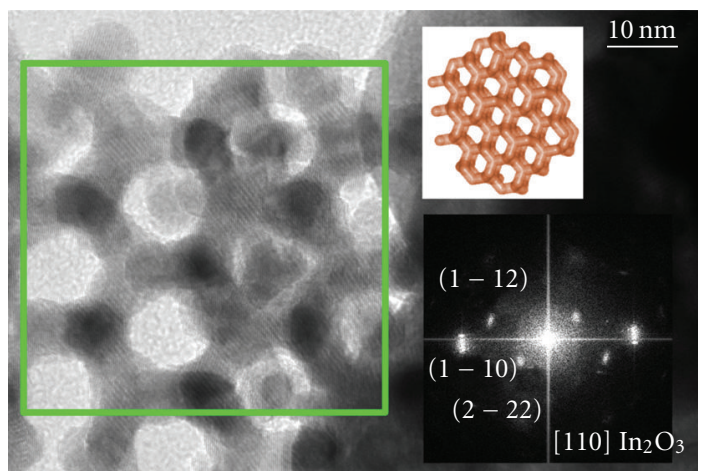

(c)

Figure 1: (a) Low angle X-ray diffractogram of mesoporous $\operatorname{In}_{2} \mathrm{O}_{3}$. Dotted line corresponds to KIT-6 silica. The replica clearly shares the same large-scale mesoporous structure with the silica template. (b) Wide angle XRD of KIT- $6 \operatorname{In}_{2} \mathrm{O}_{3}$. Main diffraction peaks of the cubic structure Ia-3 of $\mathrm{In}_{2} \mathrm{O}_{3}$ are clearly identified. (c) High-resolution Transmission Electron Microscopy and selected area diffraction pattern on the squared region of an $\operatorname{In}_{2} \mathrm{O}_{3}$ KIT-6 mesoporous replica. A sketch of the KIT-6 mesoporous structure is included for clarity (reprinted with permission from [14] Rossinyol, et al. Adv. Funct. Mater. 17, 1801-1806, 2007, Wiley-VCH Verlag GmbH \& Co. KGaA (2007)).

alumina surface. Screen-printed powders were examined on a Field Emission Hitachi 4100 scanning electron microscope.

UV illumination was provided by different LED sources, from $365 \mathrm{~nm}$ to $310 \mathrm{~nm}$, as well as a UV Xe lamp from Hamamatsu equipped with a high- and lowpass filter set. In both cases, the use of a controlled heater also allowed controlling the sensor temperature.

For the electrical characterization of the sensors, the gassensor devices were placed in a stainless steel test chamber where a controlled gaseous atmosphere was provided by means of mass flow controllers. DC electrical characterization of these devices was performed by applying an external bias and then recording the current by means of low-noise current amplifier in conjunction with a high sampling speed digital acquisition board. Most experiments were carried out also in a ProboStat cell located in a furnace or a similar item home made with $290 \mathrm{~nm}$ highpass windows. The temperature was precisely monitored and controlled by a thermocouple located next to the sample. The used gas flow ranged between 100 and $200 \mathrm{~mL} \cdot \mathrm{min}^{-1}$ without noticeable influence on the responses. Accurate gas compositions$\mathrm{NO}_{2}, \mathrm{CO}, \mathrm{N}_{2}, \mathrm{O}_{2}$, synthetic air (SA), humid air-were prepared using a gas mixer based on mass flow controllers (MFCs) controlled by computer. The sensor response was measured as the ratio of the resistance in presence and in absence of the target gas. The response was defined as $\mathrm{R}_{\text {gas }} / \mathrm{R}_{\text {air }}$ for oxidizing gases and $\mathrm{R}_{\text {air }} / \mathrm{R}_{\text {gas }}$ for reducing gases.

\section{Results and Discussion}

On the one hand, low-angle XRD patterns (Figure 1(a)) revealed that the template and the corresponding replica share the same mesoporous structure (KIT-6) and demonstrated that this was a general feature of the here-studied materials. On the other hand, wide-angle XRD patterns (Figure 1(b)) confirmed that the crystalline structure of the mesoporous $\mathrm{In}_{2} \mathrm{O}_{3}$ replicas was the cubic Ia-3 (JCPDS 60416) [13].
Figure 1(c) shows a high-resolution TEM image of an $\mathrm{In}_{2} \mathrm{O}_{3}$ replica of the KIT-6 mesoporous template that corresponds to a 3D gyroidal structure. It can be observed that the obtained material is crystalline and free of defects with branches around $7 \mathrm{~nm}$ in diameter. Specifically, the analysis of the selected area diffraction (SAED) patterns corroborated that $\operatorname{In}_{2} \mathrm{O}_{3}$ crystallizes in the cubic structure Ia-3. It is noteworthy that the analyzed region does not display any grain boundary. The material looks like a perfect single crystal trimmed according a mesoporous pattern. This porous network facilitates the diffusion of the gas across the nanostructured material.

In fact, no additional electron diffraction spots corresponding to other crystals are observed (inset in Figure 1(c)). Consequently, it can be asserted that these features are characteristic of the material at least at the scale of the analyzed region and represent the optimum scenario to study surface depletion effects caused by the charge trapped at the surface. This situation is similar to a bundle of ultrathin nanowires (less than $10 \mathrm{~nm}$ in radii) but presents an additional advantage: there are no contacts between grains (or nanowires) and, therefore, there is not any grain barrier effect. Similar structural features were observed in $\mathrm{WO}_{3}$ [13].

Figure 2 shows the change in the resistance of nanostructured $\mathrm{In}_{2} \mathrm{O}_{3}$ when it is exposed to UV light. In dark conditions, the resistance values are in the gigaohm range (almost out of the scale of our measurement equipment). Under UV illumination (light density values of several $\mathrm{W} / \mathrm{cm}^{2}$ inside the chamber), the electrical resistance decreased several orders of magnitude. It is noteworthy these enormous variations in the resistance were only rapidly reverted after a thermal treatment. Similar results were obtained for $\mathrm{WO}_{3}$ (Figure 3). For this material, UV illumination produced resistance changes of more than 8 orders of magnitude.

Often, grain boundary effects explain huge changes in the resistance of polycrystalline materials $[21,22]$. However, the HRTEM and the electron diffraction analysis of our samples do not support this assumption. Therefore, it is necessary to 


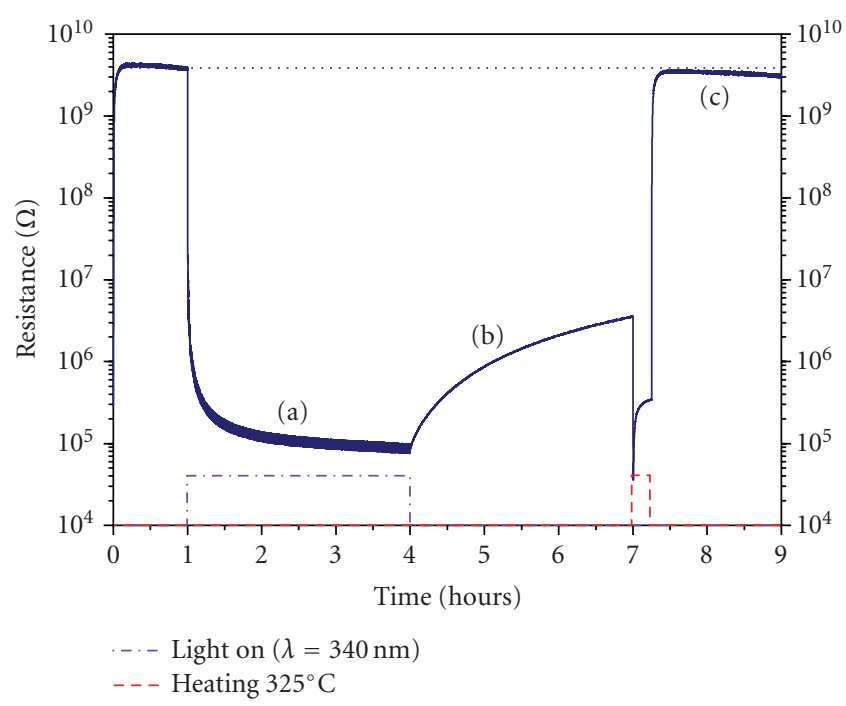

Figure 2: Resistance value variation at room temperature of an $\mathrm{In}_{2} \mathrm{O}_{3}$ nanostructured layer. Notice: (a) the resistance diminution in 4 orders of magnitude under illumination, (b) the PPC effect, and (c) the recovery of the initial value after heating for 15 minutes at $325^{\circ} \mathrm{C}$.

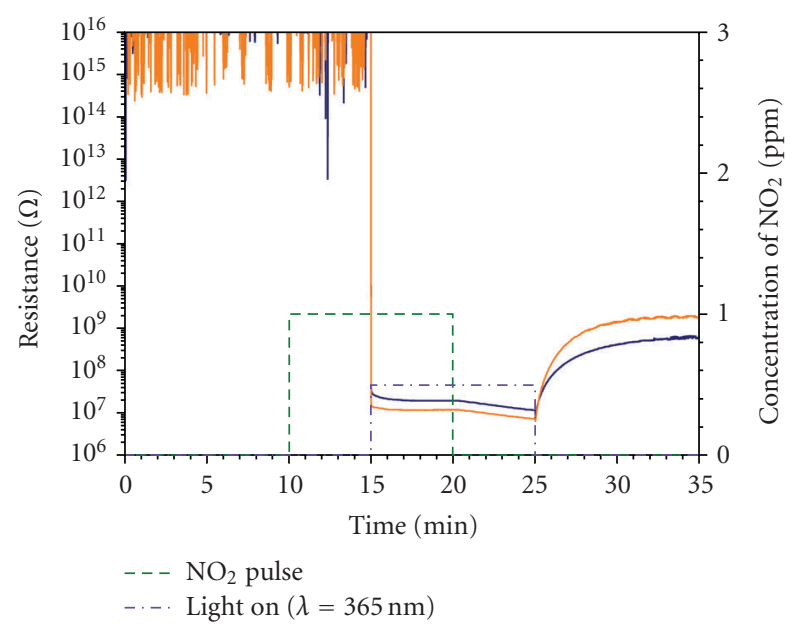

Figure 3: Resistance variation at room temperature for two similar samples of nanostructured $\mathrm{WO}_{3}$ exposed to a sequence of UV light and $\mathrm{NO}_{2}(1 \mathrm{ppm})$. The sample thickness $(300 \mu \mathrm{m})$ enlarges the response time. In dark conditions, no response was observed. The extremely high resistance cause spurious noise as resistance values approach to the limits of our equipment. After switching off the light, the PPC effect appears.

consider other explanations. Since the radii of the branches in the mesoporous network $(\sim 3.5 \mathrm{~nm})$ is comparable with the typical width of the surface depletion zone in metal oxides $(3-5 \mathrm{~nm})$ [10], it is plausible to assume an almost complete shrinkage of the conductive zone in the inner part of the material.

A detailed analysis of the transient behavior after switching on the light reveals two dynamics mechanisms. A fast one (below the second range) due to band-to-band electronhole generation followed [23] by a slow one related to gas adsorption, desorption and diffusion processes [24].

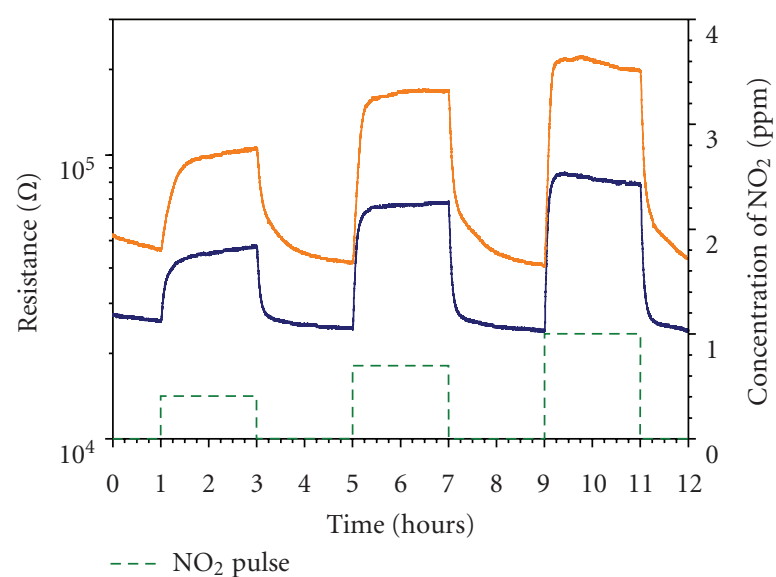

FIGURE 4: Resistance variation, at room temperature and under UV illumination $\left(\lambda=365 \mathrm{~nm}\right.$ ), of two similar samples of $\mathrm{WO}_{3}$ (KIT-6 structure) exposed to a sequence of sub ppm $\mathrm{NO}_{2}$ concentrations. Observe the baseline recovery.

Under UV illumination and at room temperature, these nanomaterials display a reversible response towards oxidizing gases which was not observed in dark conditions. According to previously reported models [25], UV illumination desorbs $\mathrm{NO}_{2}$ molecules and oxygens from the metal oxide surface leading to partially reduced surfaces $[26,27]$. In this situation, $\mathrm{NO}_{2}$ molecules and oxygens in air compete for the same adsorption sites (which are light-induced surface oxygen vacancies, according to first principles calculations [28-30]). The higher efficiency of $\mathrm{NO}_{2}$ molecules to refill the light-emptied sites explains the effective response. According to the depicted mechanism, the response to $\mathrm{NO}_{2}$ at room temperature is determined by the balance between spontaneous adsorptions and light-induced desorptions. This mechanism also explains the recovery of the response under illumination.

Two different processes may explain the photoactivated desorption of oxidizing molecules [31]. On one hand, the built-in potential near the surface of metal oxide separates the photogenerated electron-hole pairs and accumulates positive charges at the outermost layer of the materials. These holes recombine with the electrons trapped by the oxidizing molecules, and this mechanism facilitates their desorption. On the other hand, UV light can photoionize the negative charges localized at the oxidizing adsorbate, causing their direct desorption.

After this continuous photodesoprtion processes, oxidizing gases find a reduced surface which is highly reactive, even at room temperature. Therefore, the oxidizing molecules will adsorb at a rate determined by the initial density of adsorption sites (intrinsic of the material and modified by other treatments like thermal treatments [32] or functionalization [20]), and the availability of empty sites (determined by the photon and gas densities [25]).

Still under UV illumination, the steady-state occupancy of the adsorption sites by $\mathrm{NO}_{2}$ molecules determines the steady-state response of the sensor to this gas. The higher the occupancy, the more negative charge is trapped at 


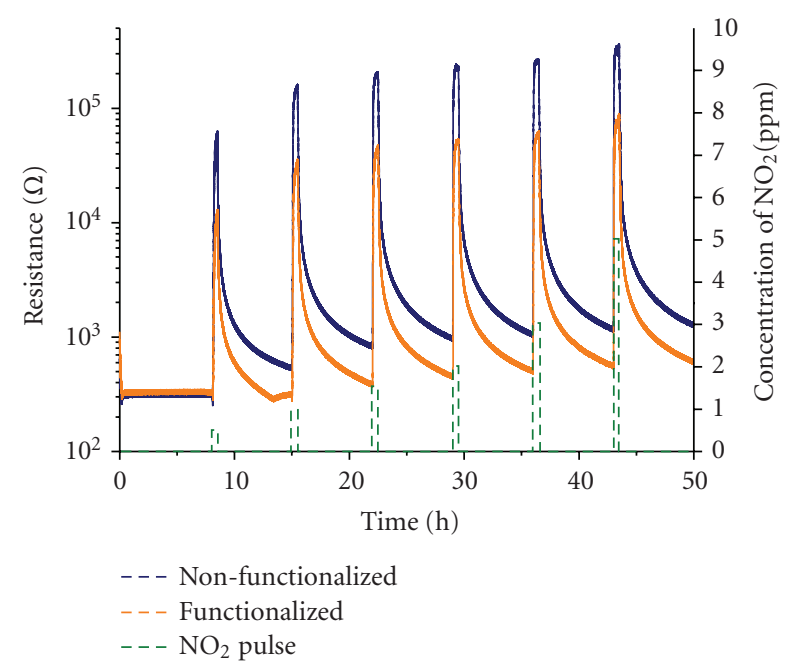

FIgURE 5: Resistance variation of a functionalized and a nonfunctionalized sensor under UV illumination $(\lambda=340 \mathrm{~nm}$, room temperature) when exposed to different concentrations of $\mathrm{NO}_{2}$. Dotted lines are only a guide for the eye.

the surface of the mesoporous structure, the wider the depletion layer and the higher the resistance is. According to most of the models used to describe the equilibrium between molecules in a gas and the corresponding adsorbed species, the occupancy (or the coverage) is a monotonously growing function of the molecule concentration in the gas phase. Even in the most simplistic approximations, like the Langmuir isotherm [33], this dependence is not linear and the occupancy tends to 1 at higher concentrations. Therefore, at low $\mathrm{NO}_{2}$ concentrations the resistance of the mesoporous network will be more sensitive to small variations of the $\mathrm{NO}_{2}$ content in air. At higher concentrations, the response will saturate and the sensor will become less sensitive. This prediction is in good agreement with the behavior experimentally observed (Figure 5). A detailed model of these phenomena will be presented elsewhere [20]. It goes without saying that these saturation effects will take place at different concentrations depending on the size of the nanocrystals.

For completeness, functionalization agents were used to block a fraction of the sites available at the materials surface. Consequently, after the treatment, the density of adsorption sites was lower than before. According to the previous model, this treatment should lower the response towards $\mathrm{NO}_{2}$ without modifying the resistance values in air and under illumination. Both predictions were corroborated experimentally (Figure 5, orange data set).

Finally, after switching off the light, the resistance does not recover the initial value (Figure 2). This new steady-state lasts for days and corresponds to the persistent photoconductivity effect (PPC), which was described elsewhere [31].

In the case of $\mathrm{WO}_{3}$, other models could partially explain the resistance reduction under UV illumination; such as the $\mathrm{W}^{6+}$ to $\mathrm{W}^{5+}$ valence change that explain the photoelectrochromic effects in this material [34]. However, the fact that equivalent behaviors were observed in two different metal oxides supports the here-proposed description.

All in all demonstrates that UV illumination is an excellent tool to reduce the surface of metal oxides in a controlled manner to improve their response towards oxidizing gases. However, heat pulses are still necessary to reset the sensors conductivity, achieving a complete surface cleaning and thus, assuring the repeatability of the measurements.

\section{Conclusions}

Shrinkage effects of the conductive zone in nanostructured metal oxides were studied with mesoporous $\mathrm{WO}_{3}$ and $\mathrm{In}_{2} \mathrm{O}_{3}$. These single crystalline materials formed branched networks with radii in range of typical width of the depleted region in metal oxides. Conductometric measurements in dark conditions indicate that the conductive zone of these materials was (almost) completely depleted (especially in $\mathrm{WO}_{3}$ samples).

Under illumination, both materials display significant response towards oxidizing gases even at room temperature. According to the depicted mechanism, illumination reduces the surface of metal oxides and facilitates a competitive behavior between the different oxidizing species in air. This mechanism is corroborated by the saturation observed in the response to high concentrations of target gases. These effects were also corroborated in functionalized materials.

In summary, it has been shown that illumination with photon energy above the band gap of the metal oxides is a powerful tool to control and regulate the occupation of the surface states. The here-presented results pave the way to the development of room temperature conductometric sensors of oxidizing gases based on a higher control of the surface states influence on the bulk conduction properties.

\section{Acknowledgment}

This work was partially supported by the Spanish Government (Projects MAGASENS (NAN2004-09380-C04-01) and N-MOSEN (MAT2007-66741-C02-01)); and the EU (Project NAWACS (NAN2006-28568-E)). JDP is indebted to the MEC for the FPU Grant.

\section{References}

[1] C. N. Xu, J. Tamaki, N. Miura, and N. Yamazoe, "Correlation between gas sensitivity and crystalline size in porous $\mathrm{SnO}_{2}$ based sensors," Chemistry Letters, vol. 3, pp. 441-444, 1990.

[2] H. Ogawa, M. Nishikawa, and A. Abe, "Hall measurement studies and an electrical conduction model of tin oxide ultrafine particle films," Journal of Applied Physics, vol. 53, no. 6, pp. 4448-4455, 1982.

[3] J. Arbiol, A. Cirera, F. Peiró, et al., "Optimization of tin dioxide nanosticks faceting for the improvement of palladium nanocluster epitaxy," Applied Physics Letters, vol. 80, no. 2, pp. 329-331, 2002.

[4] E. Comini, G. Faglia, G. Sberveglieri, Z. Pan, and Z. L. Wang, "Stable and highly sensitive gas sensors based on semiconducting oxide nanobelts," Applied Physics Letters, vol. 81, no. 10, pp. 1869-1871, 2002. 
[5] D. E. Williams and K. F. E. Pratt, "Classification of reactive sites on the surface of polycrystalline tin dioxide," Journal of the Chemical Society Faraday Transactions, vol. 94, no. 23, pp. 3493-3500, 1998.

[6] R. W. J. Scott, S. M. Yang, N. Coombs, G. A. Ozin, and D. E. Williams, "Engineered sensitivity of structured tin dioxide chemical sensors: opaline architectures with controlled necking," Advanced Functional Materials, vol. 13, no. 3, pp. 225231, 2003.

[7] A. Cabot, A. Vilà, and J. R. Morante, "Analysis of the catalytic activity and electrical characteristics of different modified $\mathrm{SnO}_{2}$ layers for gas sensors," Sensors and Actuators B, vol. 84, no. 1, pp. 12-20, 2002.

[8] F. Hernández-Ramírez, A. Tarancon, O. Casals, et al., "Electrical properties of individual tin oxide nanowires contacted to platinum electrodes," Physical Review B, vol. 16, no. 8, Article ID 085429, 2007.

[9] F. Hernández-Ramírez, A. Tarancón, O. Casals, J. Arbiol, A. Romano-Rodríguez, and J. R. Morante, "High response and stability in $\mathrm{CO}$ and humidity measures using a single $\mathrm{SnO}_{2}$ nanowire," Sensors and Actuators B, vol. 121, no. 1, pp. 3-17, 2007.

[10] C. Malagù, V. Guidi, M. Stefancich, M. C. Carotta, and G. Martinelli, "Model for Schottky barrier and surface states in nanostructured n-type semiconductors," Journal of Applied Physics, vol. 91, no. 2, pp. 808-814, 2002.

[11] E. Rossinyol, J. Arbiol, F. Peiró, et al., "Nanostructured metal oxides synthesized by hard template method for gas sensing applications," Sensors and Actuators B, vol. 109, no. 1, pp. 5763, 2005.

[12] A. Cabot, J. Arbiol, E. Rossinyol, J. R. Morante, F. Chen, and M. Liu, "Synthesis of tin oxide nanostructures with controlled particle size using mesoporous frameworks," Electrochemical and Solid-State Letters, vol. 7, no. 5, pp. G93-G97, 2004.

[13] A. Prim, E. Pellicer, E. Rossinyol, F. Peiró, A. Cornet, and J. R. Morante, "A novel mesoporous $\mathrm{CaO}$-loaded $\mathrm{In}_{2} \mathrm{O}_{3}$ material for $\mathrm{CO}_{2}$ sensing," Advanced Functional Materials, vol. 17, no. 15, pp. 2957-2963, 2007.

[14] E. Rossinyol, A. Prim, E. Pellicer, et al., "Synthesis and characterization of chromium-doped mesoporous tungsten oxide for gas-sensing applications," Advanced Functional Materials, vol. 17, no. 11, pp. 1801-1806, 2007.

[15] E. Rossinyol, E. Pellicer, A. Prim, et al., "Gadolinium doped ceria nanocrystals synthesized from mesoporous silica," Journal of Nanoparticle Research, vol. 10, no. 2, pp. 369-375, 2008.

[16] L. Fernández-Romero, J. M. Montero-Moreno, E. Pellicer, et al., "Assessment of the thermal stability of anodic alumina membranes at high temperatures," Materials Chemistry and Physics, vol. 111, no. 2-3, pp. 542-547, 2008.

[17] D. Zhao, Q. Huo, J. Feng, B. F. Chmelka, and G. D. Stucky, "Nonionic triblock and star diblock copolymer and oligomeric sufactant syntheses of highly ordered, hydrothermally stable, mesoporous silica structures," Journal of the American Chemical Society, vol. 120, no. 24, pp. 6024-6036, 1998.

[18] D. Zhao, J. Feng, Q. Huo, et al., "Triblock copolymer syntheses of mesoporous silica with periodic 50 to 300 angstrom pores," Science, vol. 279, no. 5350, pp. 548-552, 1998.

[19] F. Kleitz, S. H. Choi, and R. Ryoo, "Cubic Ia3d large mesoporous silica: synthesis and replication to platinum nanowires, carbon nanorods and carbon nanotubes," Chemical Communications, vol. 9, no. 17, pp. 2136-2137, 2003.

[20] T. Andreu, M. Manzanares, H. Mutin, et al., "Phosphanate functionalization and shrinkage effects on the gas sensing properties using metal oxides mesoporic materials," submitted.

[21] A. Diéguez, A. Vilà, A. Cabot, et al., "Influence on the gas sensor performances of the metal chemical states introduced by impregnation of calcinated $\mathrm{SnO}_{2}$ sol-gel nanocrystals," Sensors and Actuators B, vol. 68, no. 1, pp. 94-99, 2000.

[22] N. Barsan, D. Koziej, and U. Weimar, "Metal oxide-based gas sensor research: how to?" Sensors and Actuators B, vol. 121, no. 1, pp. 18-35, 2007.

[23] J. D. Prades, R. Jimenez-Diaz, F. Hernández-Ramírez, et al., "Toward a systematic understanding of photodetectors based on individual metal oxide nanowires," Journal of Physical Chemistry C, vol. 112, no. 37, pp. 14639-14644, 2008.

[24] F. Hernández-Ramírez, J. D. Prades, A. Tarancon, et al., "Insight into the role of oxygen diffusion in the sensing mechanisms of $\mathrm{SnO}_{2}$ nanowires," Advanced Functional Materials, vol. 18, no. 19, pp. 2990-2994, 2008.

[25] J. D. Prades, R. Jimenez-Diaz, F. Hernández-Ramírez, et al., "Equivalence between thermal and room temperature UV light-modulated responses of gas sensors based on individual $\mathrm{SnO}_{2}$ nanowires," Sensors and Actuators B, vol. 140, no. 2, pp. 337-341, 2009.

[26] J. D. Prades, R. Jimenez-Diaz, F. Hernández-Ramírez, et al., "On the role of the illumination conditions in the performance of room temperature gas sensors based on individual $\mathrm{SnO}_{2}$ nanowires," submitted.

[27] P. Camagni, G. Faglia, P. Galinetto, C. Perego, G. Samoggia, and G. Sberveglieri, "Photosensitivity activation of $\mathrm{SnO}_{2}$ thin film gas sensors at room temperature," Sensors and Actuators B, vol. 31, no. 1-2, pp. 99-103, 1996.

[28] J. D. Prades, A. Cirera, and J. R. Morante, "First-principles study of $\mathrm{NO}_{x}$ and $\mathrm{SO}_{2}$ adsorption onto $\mathrm{SnO}_{2}$ (110)," Journal of the Electrochemical Society, vol. 154, no. 8, pp. H675-H680, 2007.

[29] J. D. Prades, A. Cirera, J. R. Morante, J. M. Pruneda, and P. Ordejón, "Ab initio study of $\mathrm{NO}_{x}$ compounds adsorption on $\mathrm{SnO}_{2}$ surface," Sensors and Actuators B, vol. 126, no. 1, pp. 6267, 2007.

[30] M. Habgood and N. Harrison, "An ab initio study of oxygen adsorption on tin dioxide," Surface Science, vol. 602, no. 5, pp. 1072-1079, 2008.

[31] J. D. Prades, F. Hernández-Ramírez, R. Jimenez-Diaz, et al., "The effects of electron-hole separation on the photoconductivity of individual metal oxide nanowires," Nanotechnology, vol. 19, no. 46, Article ID 465501, 2008.

[32] J. D. Prades, J. Arbiol, A. Cirera, et al., "Defect study of $\mathrm{SnO}_{2}$ nanostructures by cathodoluminescence analysis: application to nanowires," Sensors and Actuators B, vol. 126, no. 1, pp. 612, 2007.

[33] M. C. Desjonquères and D. Spanjaard, Concepts in Surface Physics, Springer, Berlin, Germany, 2nd edition, 1996.

[34] G. A. Niklasson and C. G. Granqvist, "Electrochromics for smart windows: thin films of tungsten oxide and nickel oxide, and devices based on these," Journal of Materials Chemistry, vol. 17, no. 2, pp. 127-156, 2007. 

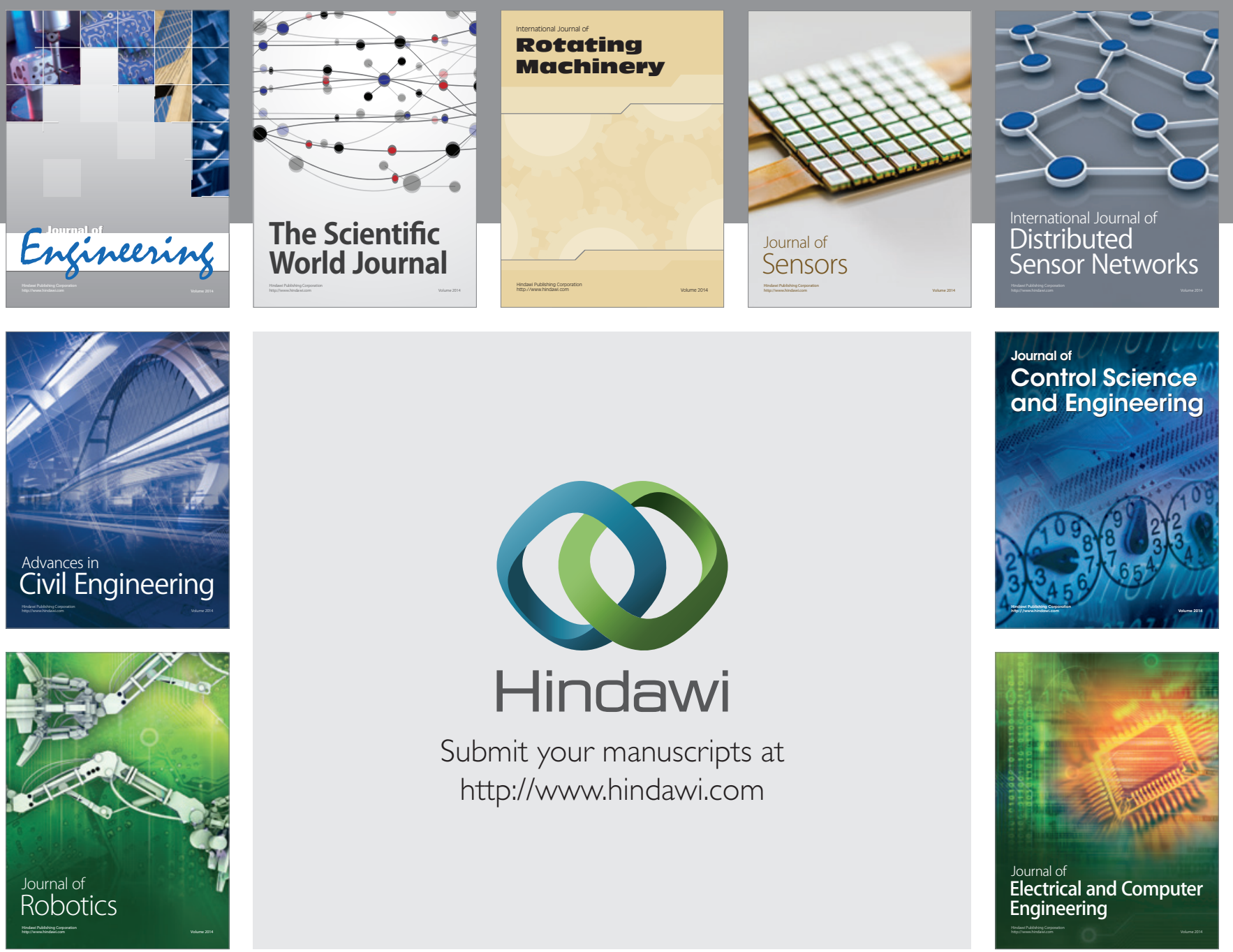

Submit your manuscripts at

http://www.hindawi.com
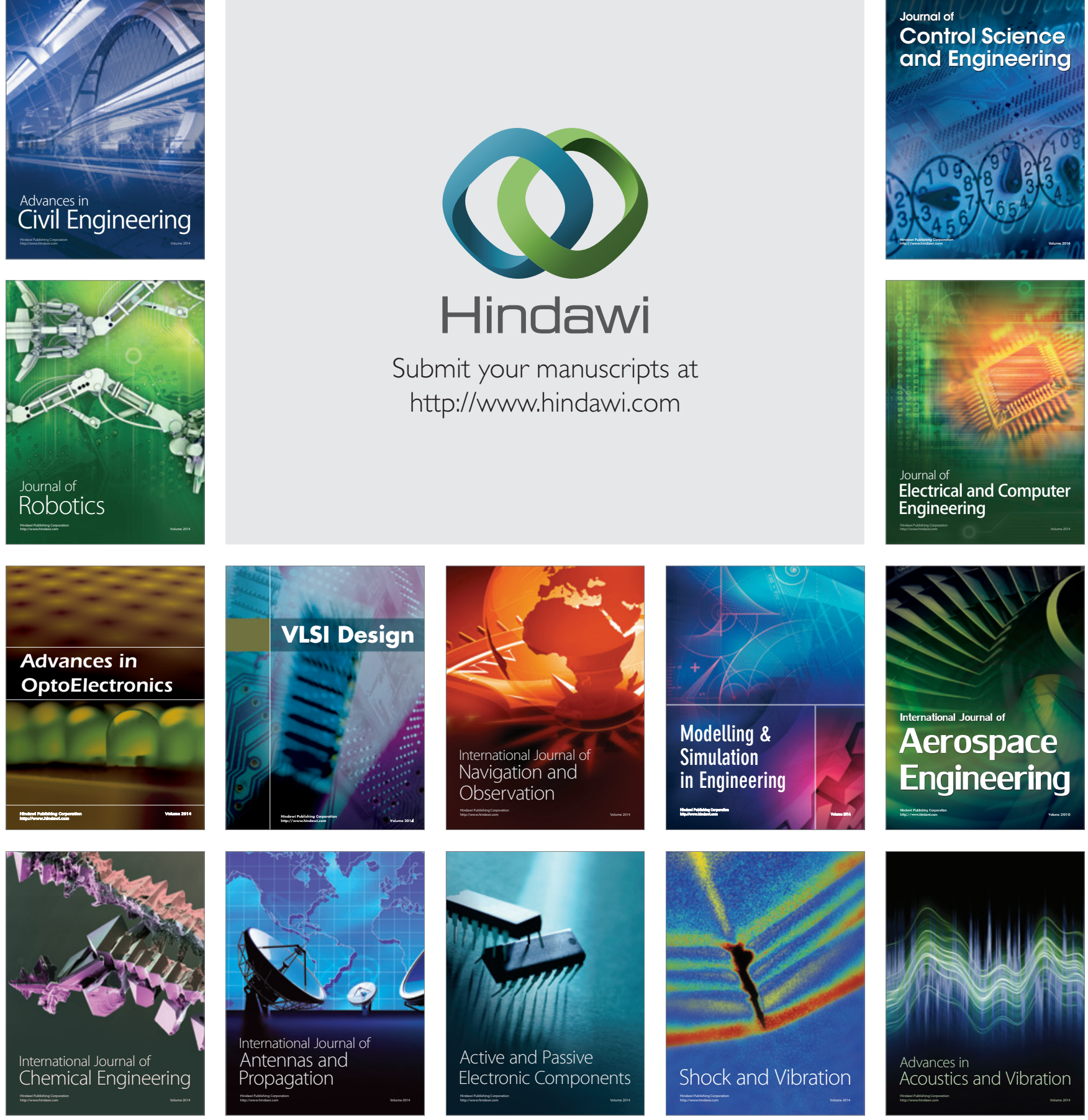